\title{
Predictors of Stress Fracture Susceptibility in Arab Female Military Recruits during Combat Training: A Preliminary Study
}

\author{
AlJawder $\mathrm{A}^{1}$, Faqi $\mathrm{MK}^{*_{2}}$, Gusbi EA ${ }^{2}$, Marshad $\mathrm{M}^{3}$ and Alkhalifa $\mathrm{F}^{4}$ \\ ${ }^{1}$ Orthopedic specialist, Department of Orthopedic Surgery, Bahrain Defence Force Hospital - Royal Medical \\ Services, Riffa, Bahrain \\ ${ }^{2}$ Orthopedic resident, Department of Orthopedic Surgery, Bahrain Defence Force Hospital - Royal Medical Services, \\ Riffa, Bahrain \\ ${ }^{3}$ Surgical resident, Department of Surgery, Bahrain Defence Force Hospital - Royal Medical Services, Riffa, Bahrain \\ ${ }^{4}$ Royal College of Surgeons in Ireland- MUB, Consultant Orthopedic and Trauma Surgeon, Head of Department of \\ Orthopedic Surgery, Bahrain Defence Force Hospital - Royal Medical Services, Riffa, Bahrain
}

${ }^{*}$ Corresponding author: Faqi MK, Orthopedic resident, Department of Orthopedic Surgery, Bahrain Defence Force Hospital - Royal Medical Services, Riffa, Bahrain, E-mail: drmfaqi@gmail.com

Citation: AlJawder A, Faqi MK, Gusbi EA, Marshad M, Alkhalifa F (2016) Predictors of Stress Fracture Susceptibility in Arab Female Military Recruits during Combat Training: A Preliminary Study. J Surg Oper Care 1(2): 206. doi: 10.15744/2455-7617.1.206

Received Date: March 16, 2016 Accepted Date: May 20, 2016 Published Date: May 23, 2016

\begin{abstract}
Introduction: Military recruits and athletes regularly engaging in vigorous physical activities are at increased risk for sustaining lower limb overuse injuries. Stress fractures represent up to $20 \%$ of all overuse injuries sustained by such populations. Risk factors of stress fractures have been recently shown to vary between different ethnic and demographic groups. The aim of this study is to evaluate risk factors of stress fractures among Arab female military recruits engaged in basic military training.

Methods: A prospective study was conducted on 108 Arab female military recruits entering 6-months Basic Military Training program in 2014-2015. During the program's orientation and pre-entry medical examination, information on age, weight, height, hemoglobin, alkaline phosphatase, serum calcium and vitamin D levels were collected. Participants were also administered a questionnaire pertaining data on marital status, age of menarche, oral contraceptive use, menstrual period pattern and use of vitamins and other supplementations. Participants sustaining lower limb injuries were further evaluated with plain radiographs and bone scans.

Results: 100 females were included in the study, of which 17 (17\%) were referred to the orthopedic clinic for further evaluation. A total of 8 participants were diagnosed with stress fractures (8\%). Stress fractures of the tibia were most common (87.5\%), followed by femur (12.5\%). Age of menarche and weight were identified as statistically significant risk factors for sustaining stress fractures. Although vitamin D deficiency was seen in $78 \%$ of participants, it did not significantly increase the risk for stress fractures.

Conclusion: Identifying risk factors for stress fractures is important in attempting to reduce their incidence. Risk factors for stress fractures vary between different ethnic populations. This is the first preliminary study to investigate risk factors for stress fractures in Arabs, and could serve as a basis for future stress fracture research in the region.
\end{abstract}

Keywords: Bone health; Female athletes; Risk factors; Stress fracture; Vitamin D

\section{Introduction}

Bone, due to its mechanical properties, has the ability to withstand certain strain magnitudes during mechanical loading, beyondwhich it fails, this is known as the point of ultimate strength. Fatigue failure occurs when repetitive loading leads to bone failure with a magnitude below its ultimate strength. In other words, the amount of strain needed for a bone to fail is reversely proportional to the rate of loading cycles. In conditions where either bone loading or the rate at which it is loaded (or both) are increased, a bone's endurance threshold is eventually breached this damage is termed a stress fracture.

Military recruits and athletes regularly engage in vigorous training. Repetitive loading to their lower extremities places them at an increased risk for sustaining lower limb overuse injuries. Of all overuse injuries sustained by athletic populations, stress fractures represent up to 20\% [1]. A large-scale study conducted on US Army Basic Combat Training recruits reported a stress fracture incidence of 19.3 and 79.9 stress fractures/1000 recruits in males and females, respectively [2]. Higher incidences, reaching up to $28.9 \%$, were also reported [3]. 
The aim of this study was to evaluate risk factors for stress fractures and to assess their impact in increasing susceptibility to stress fractures amongst Arab female military recruits. Although risk factors for stress fractures have been previously identified, differences in race and ethnicity have been shown to significantly influence the magnitude of the variable's effect. Bone research in multiethnic populations demonstrated differing bone quality, response to injury and risk factors for fractures between races $[4,5]$. Therefore, the importance of identifying ethnicity as a significant variable in studying bone health has been recognized [6].

Risk factors for stress fractures can be categorized as extrinsic and intrinsic factors, in other words modifiable and nonmodifiable factors, respectively. Whilst modifiable factors have been examined extensively in literature, recent trends are towards individualizing preventative measures according to non-modifiable factors. More preventative measures could be taken for individuals at higher risks for stress fractures due to non-modifiable factors. Extrinsic risk factors are variables that are not related to the individual participant and they increase the likelihood of injury, whereas intrinsic risk factors are characteristic variables specific to each individual candidate. However, in order to prevent stress fracture occurrence, a risk factor associated with injury must be modifiable [7]. Therefore, classifying the known intrinsic and extrinsic factors into either modifiable or non-modifiable did not only show relevance in injury prevention, but it has also shown clinical benefits [8].

\section{Material and Methods}

\section{Study design and Population selection}

The following prospective study was approved by the research and ethics committee of Bahrain Defence Force (BDF) military hospital. The population sample included all female military recruits aged 18-33 enrolling in a military training program from September 2014 till February 2015. Participants, chosen at random, were briefed on the study and written consent was obtained during the first week of the program.

Military recruits who fail to successfully complete the 6 months of basic training program, for reasons other than attaining a stress fracture, were excluded from this study.

\section{Outcome Data}

All recruits were compliant with the medical requirements of Bahrain Defence Force military, having previously passed a mandatory medical check-up by training doctors prior to starting the basic training program (BTP). The medical check-up included documentation of age, weight, height, haemoglobin level, alkaline phosphatase level, and serum calcium and vitamin D levels; amongst others. These data were collected into a safe password-protected excel sheet. Additionally, each participant was administered a questionnaire pertaining data on marital status, age of menarche, oral contraceptive use, menstrual period pattern and use of vitamins and other supplementations.

The recruits were there after followed through the six-month period of the training program for occurrence of any musculoskeletal injuries, with particular focus on stress fractures. Military training doctors were the first to assess injuries; they were to refer participants with symptoms of fractures and/or stress fractures to the BDF hospital, where senior orthopaedic residents further evaluated participants. The training officer in-charge was responsible for documenting details of the injuries for each recruit, including date and site of injury, initial and final diagnoses; and patients outcome.

Subjects who complained of persistent bone pain were followed up in the orthopaedic clinic. Diagnosis of a stress fracture was based on: a) clinical presentation pain of sudden onset without previous trauma which is exacerbated and worsened by repetitive physical activity, a confirmatory plain radiograph (X-ray) and followed by a SPECT bone scan (e.cam Signature Series; Siemens Healthcare) (Figure1 and 2).
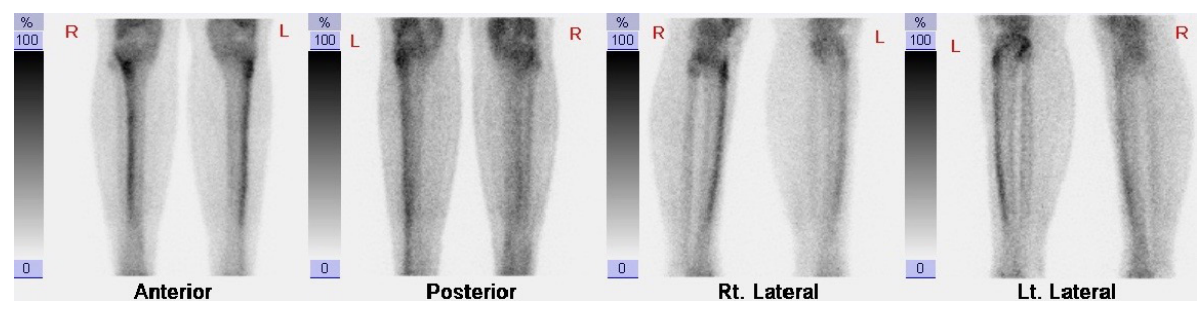

Figure 1: SPECT bone scan image showing increased uptake over the tibial shafts consistent with shin splints

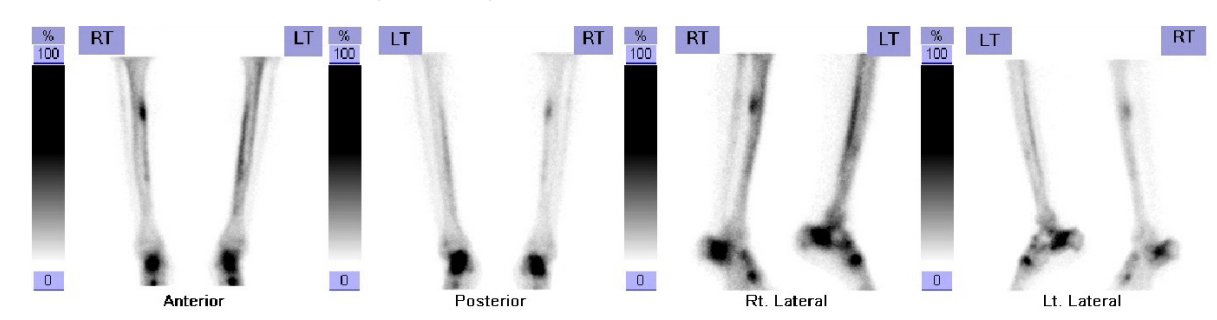

Figure 2: SPECT bone scan images showing stress fracture of the right tibial shaft 


\section{Variables}

Anthropometric measurement: Anthropometric measurements of weight and height were obtained from medical records. BMI was then calculated by dividing the weight in $\mathrm{Kg}$ by the squared height in meters. Findings were displayed in a table and plotted in a line graph.

Laboratory investigations: Serum levels of haemoglobin, alkhaline phosphatase, calcium and vitamin D were obtained for each participant prior to commencing the basic training program.

Questionnaire Measurements: Prior to starting the basic training program, participants were administered a paper questionnaire. The questionnaire included basic demographic information and presence of risk factors and co-morbidities. Risk factors included reproductive and menstrual cycle history, such as age of menarche, date of last menstrual cycle, frequency of the cycle/annum, marital status, gravidity and use of oral contraceptive pills (OCPs). Additionally, the questionnaire addressed physical activity and exercise behaviour prior to BTP. The questionnaire also assessed the participants' diet (dairy food consumption) and use of vitamin D and calcium supplements. Finally, participants were also surveyed for previous history of lower extremity overuse injuries and stress fractures. Any medical illness and medications were documented.

Statistical Analysis: Data were analyzed with IBM SPSS statistics software version 16.0 (IBM Corporation, New York, USA). The descriptive analysis of the data was expressed as mean, SD, frequency and percentage. Statistical comparisons of means were calculated using a student's t test. For multivariate analysis, a multiple logistic regression analysis was performed, with stress fractures as the dependent variable and the assessed risk factors as independent variables. $\mathrm{P}<0.05$ was considered statistically significant.

\section{Results}

Of the 108 female military recruits initially enrolled in this study, 8 were excluded from this study as they expelled or withdrew form the basic training program for reasons that were unrelated to this study. Participants who were excluded from the study were also excluded form statistical analyses. Basic and demographic characteristics of the 100 recruits that successfully completed the study are shown in Table 1.

\begin{tabular}{|c|c|}
\hline Variables & Mean \pm SD \\
\hline Age & $22.13 \pm 2.80$ \\
\hline Weight & $59.79 \pm 8.82$ \\
\hline Height & $158.45 \pm 5.0$ \\
\hline Body Mass Index $\left(\mathbf{k g} / \mathbf{m}^{2}\right)$ & $23.81 \pm 3.31$ \\
\hline Haemoglobin $\mathbf{( g / d L )}$ & $11.88 \pm 1.06$ \\
\hline Alkaline Phosphatase (IU/L) & $77.53 \pm \mathbf{1 8 . 0 8}$ \\
\hline Vitamin D (ng/ml) & $26.87 \pm 23.80$ \\
\hline Menarche (years) & $13.13 \pm 1.38$ \\
\hline Time since Menarche (years) & $9.0 \pm 0.299$ \\
\hline Marital status n (\%) & \\
\hline Single & $75(75.0)$ \\
\hline Married & $25(25.0)$ \\
\hline Period, $\mathbf{n}(\%)$ & \\
\hline Regular & $88(88.0)$ \\
\hline Irregular & $12(12.0)$ \\
\hline Oral Contraceptives $\mathbf{n}(\%)$ & \\
\hline Yes & $\mathbf{3 ( 3 . 0 )}$ \\
\hline No & $97(97.0)$ \\
\hline
\end{tabular}

Table 1: The demographic characteristics of the sample population $(\mathrm{N}=100)$

During the 6-month of basic training program, 17 of the 100 participants (17\%) were referred to the orthopedic clinic with the following complaints: 5 with knee pain (5\%), 2 with hip pain (2\%), 8 with leg pain (8\%) and 2 with ankle pain (2\%). A total of 8 participants were diagnosed with stress fractures (8\%). Stress fractures of the tibia were most common $(\mathrm{n}=7,87.5 \%)$, followed by femur $(\mathrm{n}=1,12.5 \%)$. Of the 8 participants sustaining stress fractures, 5 had bilateral stress fractures $(62.5 \%)$ and 3 had unilateral stress fractures $(37.5 \%)$. 
Mean and SD of the selected demographic and physical characteristics were calculated using a student's t test and presented in Table 2 according to stress fracture status. A logistic regression analysis was performed to assess the effects of age, weight, BMI, height, hemoglobin, ALP, calcium, vitamin D, age of menarche, marital status, OCP use and menstrual period on stress fracture (Table 3). The model explained $70.4 \%$ of variance of stress fracture. Married women were 1.428 times more likely to exhibit stress fracture than single women. Women with irregular periods had a higher risk for developing a stress fracture (Figure 3).

\begin{tabular}{|c|c|c|c|c|c|c|}
\hline & \multicolumn{3}{|c|}{ No Stress Fracture } & \multicolumn{2}{|c|}{ Stress fracture } & \multirow[b]{2}{*}{$\begin{array}{c}\text { Std. } \\
\text { Deviation }\end{array}$} \\
\hline & $\mathbf{N}$ & Mean & $\begin{array}{c}\text { Std. } \\
\text { Deviation }\end{array}$ & $\mathbf{N}$ & Mean & \\
\hline Age & 92 & 22.0 & 2.70325 & 8 & 23.5 & 3.77964 \\
\hline Weight $(\mathrm{Kg})^{*}$ & 92 & 58.8 & 8.27273 & 8 & 71.0 & 7.40656 \\
\hline Body Mass Index $\left(\mathrm{kg} / \mathrm{m}^{2}\right)$ & 92 & 23.4 & 3.02547 & 8 & 29.0 & 1.84303 \\
\hline Height $(\mathrm{cm})$ & 92 & 158.6 & 5.05946 & 8 & 156.4 & 3.88909 \\
\hline Haemoglobin (g/dL) & 92 & 11.9 & 1.08225 & 8 & 11.9 & 0.86839 \\
\hline Alkaline Phosphatase (IU/L) & 92 & 77.7 & 17.78191 & 8 & 75.8 & 22.62584 \\
\hline Vitamin D (ng/ml) & 92 & 27.7 & 24.75216 & 8 & 17.5 & 4.93644 \\
\hline Menarche $^{\star}$ & 92 & 13.2 & 1.39722 & 8 & 12.1 & 0.64087 \\
\hline
\end{tabular}

${ }^{*} \mathrm{p}<0.05$ (Statistically significant)

Table 2: Mean and SD of the selected demographic and physical characteristics by stress fracture status

\begin{tabular}{|c|c|c|c|c|c|c|c|c|}
\hline Variable & B & S.E. & Wald & df & Sig. & Exp(B) & \multicolumn{2}{|c|}{ 95\% C.I.for EXP(B) } \\
\hline Age & & & & & & Lower & Upper \\
\hline Weight & 0.16 & 0.34 & 0.23 & 1 & 0.63 & 1.17 & 0.61 & 2.27 \\
\hline BMI & 0.00 & 5.73 & 0.00 & 1 & 1.00 & 1.00 & 0.00 & 75651.55 \\
\hline Height & -0.57 & 2.07 & 0.07 & 1 & 0.78 & 0.57 & 0.01 & 33.05 \\
\hline Haemoglobin & 0.68 & 0.64 & 1.13 & 1 & 0.29 & 1.97 & 0.56 & 6.90 \\
\hline Alkaline Phosphatase & 0.04 & 0.06 & 0.43 & 1 & 0.51 & 1.04 & 0.92 & 1.17 \\
\hline Calcium & -1.54 & 6.50 & 0.06 & 1 & 0.81 & 0.22 & 0.00 & 73582.15 \\
\hline Vitamin D & -0.17 & 0.24 & 6.52 & 1 & 0.47 & 0.84 & 0.52 & 1.35 \\
\hline Menarche & -1.17 & 0.98 & 1.41 & 1 & 0.23 & 0.31 & 0.05 & 2.14 \\
\hline Marital status & 0.36 & 1.45 & 0.06 & 1 & 0.81 & 1.43 & 0.08 & 24.70 \\
\hline OCP use & -0.80 & 4.52 & 0.03 & 1 & 0.86 & 0.45 & 0.00 & 3183.94 \\
\hline Period & 2.54 & 1.59 & 2.56 & 1 & 0.11 & 12.69 & 0.57 & 284.17 \\
\hline Constant & 73.12 & 327.67 & 0.05 & 1 & 0.82 & 56.56 & & \\
\hline
\end{tabular}

Table 3: Stress fracture incidence and OR by demographic, physical body structure

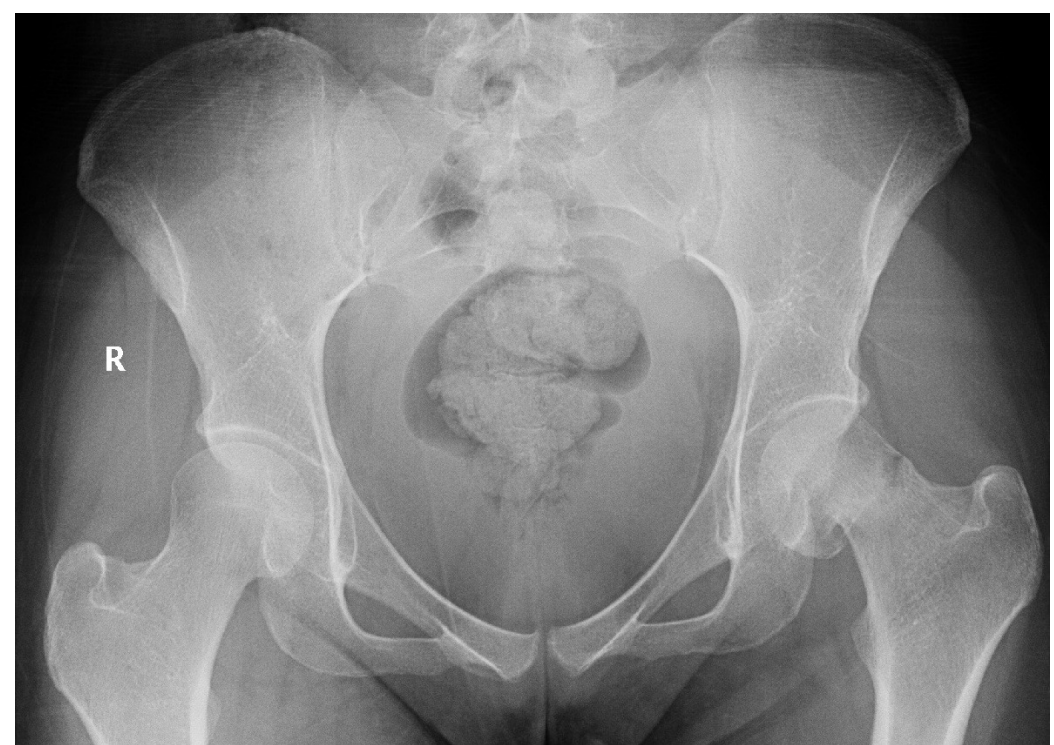

Figure 3: Plane radiograph of the pelvis and both hips showing stress fracture of the left neck of femur with a varus deformity 


\section{Discussion}

Although non-modifiable risk factors for stress fractures cannot be altered, their importance lies in identifying individuals at higher risks of injury [8]. Females have been shown to have a significantly higher risk of sustaining stress fractures when compared with males [2]. During 13 weeks of US Marine Corps basic training, 5\% to 7\% of female recruits sustained stress fractures [9,10]. On the other hand, an incidence of 3\% was reported in a sample of male recruits from the US Marine Corps 12-weeks basic training [11]. Similarly, during UK Army recruits basic training; stress fracture incidence was $10.9 \%$ in females versus $3 \%$ in males [12].

Menstrual irregularities and age at menarche have been previously associated with stress fractures. We found that age of menarche was strongly associated with risk of stress fracture. Females who had earlier ages of menarche were significantly more likely to develop a stress fracture $(\mathrm{p}<0.05)$. Contrarily, Tenforde, et al. reported a higher risk of stress fracture in females with late menarche (15 years or older, $\mathrm{p}=0.01$ ) [13]. Moreover, Australian female athletes who suffered from stress fractures all had a later age of menarche and fewer menstrual cycles/year, compared to controls [14,15]. A review of 207 female collegiate athletes found a stress fracture incidence 3.3 times higher in those with irregular menses [16]. In the US Army, a survey of 1630 women showed that those with amenorrhea of more than 6 months experienced one or more stress fractures [17].

Ethnicity is another non-modifiable risk factor for stress fractures. Multiethnic studies of the American Army reported significantly higher risks for stress fractures in Caucasians, when compared to blacks [17-19]. Furthermore, in spite of their lower serum vitamin $\mathrm{D}$ levels, black females have shown higher bone mineral density on dual energy x-ray absorptiometry compared to white females [20]. This means that bone quality and mineral density could be attributed to factors other than vitamin D levels. Hence, the decreased risk seen in Blacks [21]. Black individuals are believed to have adaptive responses to low vitamin D levels which are protective against skeletal injuries [20].

Calcium and Vitamin D are essential for bone health [22]. Inadequate levels of calcium and vitamin D are associated with an increased risk of osteoporosis, osteomalacia, and stress fractures [22-24]. In a randomized double-blind placebo-control study of 5201 female Navy recruits during 8 weeks of basic training, Lappe, et al. found that subjects receiving calcium and vitamin D supplementation had a $20 \%$ lower incidence of stress fractures compared to controls receiving placebo [23]. However, in our study, $21 \%$ and $78 \%$ of participants had vitamin D sufficiency and deficiency, respectively. This endemic of hypovitaminosis D is in lieu with published literature on vitamin D levels in Arabs [25-27]. However, with such high prevalences of hypovitaminosis D in Arab populations, and because vitamin $\mathrm{D}$ was not shown to be a significant risk factor to stress fractures in our study population, we hypothesize an adaptive response present in Arabs, similar to that seen in Blacks which warrants further investigations [20,21]. Moreover, the high prevalence of hypovitaminosis D seen in Arabs could be attributed to cultural conservative clothing and decreased outdoors activities; sun exposure, due to high temperatures in Arab countries [28]. Nevertheless, low vitamin D levels were also reported in Arab-American females living in Michigan which again emphasizes the need for further investigations [29].

In analyzing stress fractures in our population, the tibia was the most common injury site (87.5\%), followed by the neck of femur (12.5\%). This is in accordance with published literature. Armstrong, et al. reported that 50\% of stress fractures occurred in the tibia. Of all stress fractures, the tibia was the commonest site in males (72.2\%) and females (100\%) [30]. Similarly, in a study of US Marine Corps, stress fractures of the tibia represented $71 \%$ of stress fractures [31]. In investigating the biomechanical factors associated with stress fractures, Milner, et al. conducted a large cohort study of female runners over 4 years. They noticed that the stress fracture group had increased average vertical loading forces acting on their tibias. This was due to their knees having a greater valgus angle, internal rotation and sagittal knee stiffness, compared to others [32,33]. Moreover, foot structure, knee kinematics and biomechanical movement patterns have been associated with stress fractures and their locations [34].

Recently, genetic variations in vitamin D receptors (VDR) have been associated with stress fractures. Fokl and Bsml polymorphisms of the VDR gene can decrease bone content and have been shown to increase the risk of stress fractures in Caucasians and Spanish individuals, amongst other populations [35-37]. He, et al. found that vitamin D receptor gene variations influence bone mineral density and osteoporosis [38]. Genetic variations in vitamin D receptors in Arabs have not been previously investigated. The high prevalence of hypotivaminosis D found in Arabs warrants future studies into the presence of specific genetic variations in vitamin $\mathrm{D}$ receptors.

We found that weight and BMI were both associated with stress fractures. Females with higher weights and BMIs were more likely to develop stress fractures. This is contrary to Tenforde, et al. who reported that females with low BMI $(<19)$ were at three times greater risk of sustaining a stress fracture $(\mathrm{p}<0.05)$ [13]. A higher BMI was also shown to be protective against the development of stress fractures in females during BCT [2]. Thinner women and females losing weight have been shown to exhibit more rapid bone loss and decreased bone mass density (BMD) which is the rationale behind such results [39]. Nevertheless, mechanical loading is an essential stimulus to bone formation through increasing osteoblasts and osteoclasts differentiation [40]. A high BMI can either be due to lean mass or adiposity, in which each has its influence on bone. It is well established that dynamic load exerted from muscle contraction is more anabolic to bone than static load [41]. Also, skeletal unloading from immobilization and inactivity was found to increase adipocyte differentiation and inhibit osteoblastic differentiation [42]. Furthermore, higher adiposity is highly associated with decreasing the rate of bone formation [43]. Finally, research has shown that in attempting to reduce weight, caloric 
restriction exerts a harmful effect to bone health whilst exercise plays a protective role through stimulating bone formation $[44,45]$. In summary, obesity on its own does not provide mechanical advantage to bone if not accompanied by greater lean mass and physical activity. Therefore, body composition would probably be a more specific tool than BMI in evaluating stress fractures risk. Although we found that females with higher BMI were at higher risks of developing stress fractures, contradicting previous studies, this rationale serves as a valid explanation, which warrants further investigations.

The most important limitation to our study is the relatively small sample size. Due to such small sample size, the risk factors for stress fractures in female Arabs could not be fully appreciated. Nevertheless, our preliminary data suggests that risk factors for stress fractures in female Arabs might differ from those of other ethnic populations. Therefore, we recommend the study of these risk factors in larger populations.

\section{Conclusion}

Identifying risk factors for stress fractures is important in attempting to reduce their incidence. Risk factors for stress fractures vary between different ethnic populations. This is the first preliminary study to investigate risk factors for stress fractures in Arabs, and could serve as a basis for future stress fracture research in the region.

\section{Acknowledgements}

We would like to thank Maj. Gen. Prof. Khalid Bin Ali Al-Khalifa for his continuous support and encouragement towards research at the Royal Medical Services, Bahrain Defence Force hospital. We thank the medical battalion at the Royal Medical Services for their interests and inputs in our research project. Last, but not least, we thank Maj. (Dr.) Ahmed AlAnsari and Ms. Aaruni Suresh for statistical support.

\section{References}

1. Snyder RA, Koester MC, Dunn WR (2006) Epidemiology of stress fractures. Clin Sports Med 25: 37-52.

2. Knapik J, Montain SJ, McGraw S, Grier T, Ely M, et al. (2012) Stress fracture risk factors in basic combat training. Int J Sports Med 33: 940-6.

3. Bennell KL, Brukner PD (1997) Epidemiology and site specificity of stress fractures. Clin Sports Med 16: 179-96.

4. Cauley JA, Wu L, Wampler NS, Barnhart JM, Allison M, et al. (2007) Clinical risk factors for fractures in multi-ethnic women: the Women's Health Initiative. J Bone Miner Res 22: 1816-26.

5. Cauley JA, Danielson ME, Boudreau R, Barbour KE, Horwitz MJ, et al. (2011) Serum 25-hydroxyvitamin D and clinical fracture risk in a multiethnic cohort of women: the Women's Health Initiative (WHI). J Bone Miner Res 26: 2378-88.

6. Montain SJ, McGraw SM, Ely MR, Grier TL, Knapik JJ (2013) A retrospective cohort study on the influence of UV index and race/ethnicity on risk of stress and lower limb fractures. BMC Musculoskelet Disord 14: 135

7. Jones BH, Thacker SB, Gilchrist J, Kimsey CD, Sosin DM (2002) Prevention of lower extremity stress fractures in athletes and soldiers: a systematic review. Epidemiol Rev 24: 228-47.

8. Cameron KL (2010) Commentary: Time for a paradigm shift in conceptualizing risk factors in sports injury research. J Athl Train 45: 58-60.

9. Shaffer RA, Rauh MJ, Brodine SK, Trone DW, Macera CA (2006) Predictors of stress fracture susceptibility in young female recruits. Am J Sports Med 34: 108-15.

10. Rauh MJ, Macera CA, Trone DW, Shaffer RA, Brodine SK (2006) Epidemiology of stress fracture and lower-extremity overuse injury in female recruits. Med Sci Sports Exerc 38: 1571-7.

11. Beck TJ, Ruff CB, Shaffer RA, Betsinger K, Trone DW, et al. (2000) Stress fracture in military recruits: gender differences in muscle and bone susceptibility factors. Bone 27: 437-44.

12. Macleod MA, Houston AS, Sanders L, Anagnostopoulos C (1999) Incidence of trauma related stress fractures and shin splints in male and female army recruits: retrospective case study. BMJ 318: 29.

13. Tenforde AS, Sayres LC, McCurdy ML, Sainani KL, Fredericson M (2013) Identifying sex-specific risk factors for stress fractures in adolescent runners. Med Sci Sports Exerc 45: 1843-51.

14. Bennell KL, Malcolm SA, Thomas SA, Reid SJ, Brukner PD, et al. (1996) Risk factors for stress fractures in track and field athletes. A twelve-month prospective study. Am J Sports Med 24: 810-8.

15. Bennell KL, Malcolm SA, Thomas SA, Ebeling PR, McCrory PR, et al. (1995) Risk factors for stress fractures in female track-and-field athletes: a retrospective analysis. Clin J Sport Med 5: 229-35.

16. Lloyd T, Triantafyllou SJ, Baker ER, Houts PS, Whiteside JA, et al. (1986) Women athletes with menstrual irregularity have increased musculoskeletal injuries. Med Sci Sports Exerc 18: 374-9.

17. Friedl KE, Nuovo JA, Patience TH, Dettori JR (1992) Factors associated with stress fracture in young army women: indications for further research. Mil Med 157: 334-8.

18. Brudvig TJ, Gudger TD, Obermeyer L (1983) Stress fractures in 295 trainees: a one-year study of incidence as related to age, sex, and race. Mil Med 148: 666-7.

19. Gardner LI, Dziados JE, Jones BH, Brundage JF, Harris JM, et al. (1988) Prevention of lower extremity stress fractures: a controlled trial of a shock absorbent insole. Am J Public Health 78: 1563-7.

20. Harris SS (2006) Vitamin D and African Americans. J Nutr 136: 1126-9.

21. Barrett JA, Baron JA, Karagas MR, Beach ML (1999) Fracture risk in the U.S. Medicare population. J Clin Epidemiol 52: $243-9$.

22. Friedl KE, Evans RK, Moran DS (2008) Stress fracture and military medical readiness: bridging basic and applied research. Med Sci Sports Exerc 40: S609-22.

23. Lappe J, Cullen D, Haynatzki G, Recker R, Ahlf R, et al. (2008) Calcium and vitamin d supplementation decreases incidence of stress fractures in female navy recruits. J Bone Miner Res 23: 741-9. 
24. Ruohola JP, Laaksi I, Ylikomi T, Haataja R, Mattila VM, et al. (2006) Association between serum 25(OH)D concentrations and bone stress fractures in Finnish young men. J Bone Miner Res 21: 1483-8.

25. Elsammak MY, Al-Wosaibi AA, Al-Howeish A, Alsaeed J (2010) Vitamin d deficiency in Saudi Arabs. Horm Metab Res 42: 364-8.

26. Alsuwadia AO, Farag YM, Al Sayyari AA, Mousa DH, Alhejaili FF, et al. (2013) Prevalence of vitamin D deficiency in Saudi adults. Saudi Med J 34: 814-8.

27. Oren Y, Shapira Y, Agmon-Levin N, Kivity S, Zafrir Y, et al. (2010) Vitamin D insufficiency in a sunny environment: a demographic and seasonal analysis. Isr Med Assoc J 12: 751-6.

28. Glerup H, Mikkelsen K, Poulsen L, Hass E, Overbeck S, et al. (2000) Commonly recommended daily intake of vitamin D is not sufficient if sunlight exposure is limited. J Intern Med 247: 260-8.

29. Hobbs RD, Habib Z, Alromaihi D, Idi L, Parikh N, et al. (2009) Severe vitamin D deficiency in Arab-American women living in Dearborn, Michigan. Endocr Pract 15: 35-40.

30. Armstrong DW, Rue JP, Wilckens JH, Frassica FJ (2004) Stress fracture injury in young military men and women. Bone 35: 806-16.

31. Giladi M, Ahronson Z, Stein M, Danon YL, Milgrom C (1985) Unusual distribution and onset of stress fractures in soldiers. Clin Orthop Relat Res 192: 142-6.

32. Milner CE, Hamill J, Davis I (2007) Are knee mechanics during early stance related to tibial stress fracture in runners? Clin Biomech (Bristol, Avon) 22: 697703.

33. Milner CE, Ferber R, Pollard CD, Hamill J, Davis IS (2006) Biomechanical factors associated with tibial stress fracture in female runners. Med Sci Sports Exerc 38: $323-8$.

34. Cameron K, Peck K, Owens B, Svoboda S, Padua D, et al. (2013) Biomechanical Risk Factors for Lower Extremity Stress Fracture. Orth J Sports Med DOI: $10.1177 / 2325967113500019$.

35. Gao J, Wang L, Zhu J (2015) Influence of BsmI polymorphism in vitamin D receptor gene on the risk of fracture in Caucasian populations: a meta analysis. Int J Clin Exp Med 8: 589-97.

36. Chatzipapas C, Boikos S, Drosos GI, Kazakos K, Tripsianis G, et al. (2009) Polymorphisms of the vitamin D receptor gene and stress fractures. Horm Metab Res 41: 635-40.

37. Pedrera-Canal M, Moran JM, Vera V, Roncero-Martin R, Lavado-Garcia JM, et al. (2015) Lack of Influence of Vitamin D Receptor BsmI (rs1544410) Polymorphism on the Rate of Bone Loss in a Cohort of Postmenopausal Spanish Women Affected by Osteoporosis and Followed for Five Years. PLoS One 10: e0138606.

38. He W, Liu M, Huang X, Qing Z, Gao W (2015) The influence of vitamin D receptor genetic variants on bone mineral density and osteoporosis in Chinese postmenopausal women. Dis Markers DOI: org/10.1155/2015/760313.

39. Nguyen TV, Sambrook PN, Eisman JA (1998) Bone loss, physical activity, and weight change in elderly women: the Dubbo Osteoporosis Epidemiology Study. J Bone Miner Res 13: 1458-67.

40. Ehrlich PJ, Noble BS, Jessop HL, Stevens HY, Mosley JR, et al. (2002) The effect of in vivo mechanical loading on estrogen receptor alpha expression in rat ulnar osteocytes. J Bone Miner Res 17: 1646-55.

41. Turner CH, Pavalko FM (1998) Mechanotransduction and functional response of the skeleton to physical stress: the mechanisms and mechanics of bone adaptation. J Orthop Sci 3: 346-55.

42. Ahdjoudj S, Lasmoles F, Holy X, Zerath E, Marie PJ (2002) Transforming growth factor beta2 inhibits adipocyte differentiation induced by skeletal unloading in rat bone marrow stroma. J Bone Miner Res 17: 668-77.

43. Papakitsou EF, Margioris AN, Dretakis KE, Trovas G, Zoras U, et al. (2004) Body mass index (BMI) and parameters of bone formation and resorption in postmenopausal women. Maturitas 47: 185-93.

44. Shapses SA, Riedt CS (2006) Bone, body weight, and weight reduction: what are the concerns? J Nutr 136: 1453-6.

45. Kohrt WM, Barry DW, Schwartz RS (2009) Muscle forces or gravity: what predominates mechanical loading on bone? Med Sci Sports Exerc 41: 2050-5.

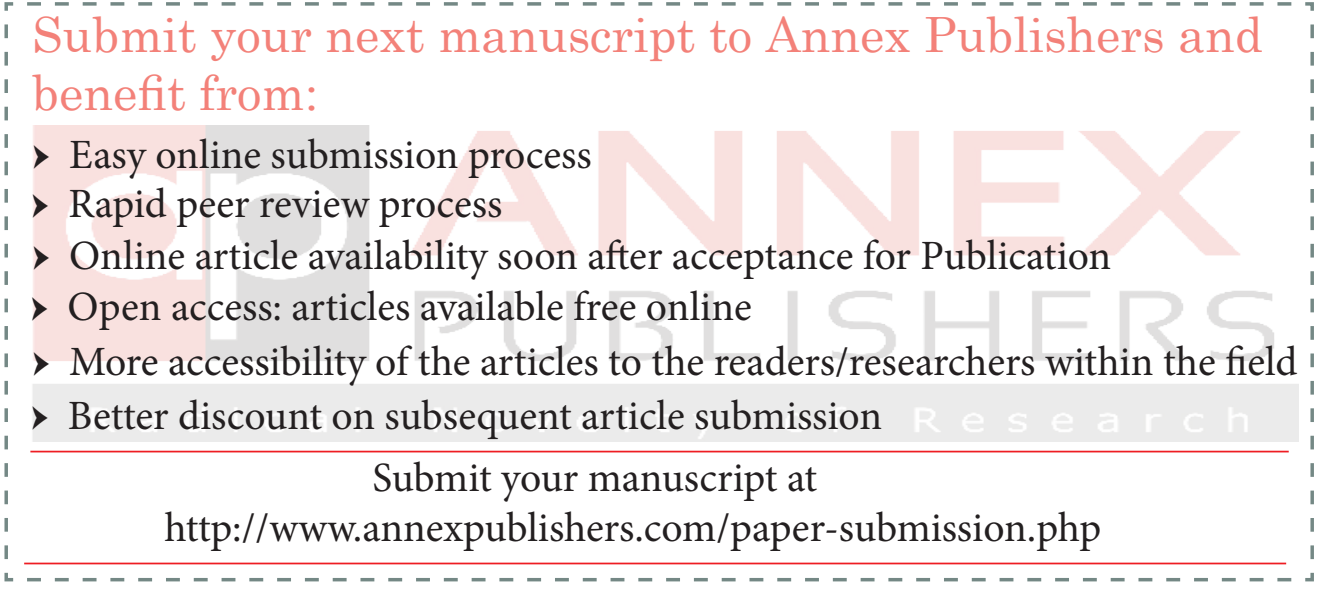

